\title{
Discrepancy between clinical and histological effects of DHA supplementation in a rat model of pouchitis
}

\author{
Sławomira Drzymała-Czyż ${ }^{1,2}$, Tomasz Banasiewicz ${ }^{3}$, Małgorzata Tubacka ${ }^{1}$, \\ Aneta Tarasiuk-Rusek ${ }^{2}$, Przemysław Majewski ${ }^{4}$, Michał Drews ${ }^{3}$, Jarosław Walkowiak ${ }^{1,2}$ \\ ${ }^{1}$ Department of Human Nutrition and Hygiene, Poznan University of Life Sciences, Poznan, Poland \\ ${ }^{2} 1^{\text {st }}$ Chair of Pediatrics, Department of Pediatric Gastroenterology and Metabolism, \\ Poznan University of Medical Sciences, Poznan, Poland \\ ${ }^{3}$ Chair of General Gastroenterological and Endocrinological Surgery, \\ Poznan University of Medical Sciences, Poznan, Poland \\ ${ }^{4}$ Department of Clinical Pathomorphology, Poznan University of Medical Sciences, Poznan, Poland
}

\begin{abstract}
Docosahexaenoic acid (DHA) potentially modulates inflammatory processes. Therefore, the aim of this study was to determine the influence of DHA supplementation on the expression of intestinal inflammation and nutritional status in rats which have undergone restorative proctocolectomy. Twenty-four Wistar rats were operated. After the induction of pouchitis, animals were randomly divided into a control group (CG) and supplementation groups receiving respectively a semi-synthetic diet without or with DHA (in a lower or higher dose, respectively known as the lower dose, $\mathrm{LD}$, and higher dose, HD, groups) for six weeks. Selected nutritional parameters were assessed. Histopathological and immunohistochemical analysis of pouch mucosa specimens was also performed. The effectiveness of feeding and quality of stools were significantly better in the HD group than in the CG. The intensity of inflammation (Moskovitz scale) was higher in HD and LD than in CG ( $p=0.03$ and $p=0.0006$, respectively). Nevertheless, pouch adaptation (Laumonier scale) was more significant in LD than in CG $(p=0.007)$. On the other hand, tissue expression of IL- $1 \alpha$ and IL-10 was higher in HD and LD than in CG (IL-1 $\alpha, p=0.009$ and $p=0.05$, respectively; IL-10, $p=0.04$ for both). DHA supplementation has no impact on body weight gain. Yet it seems that it may improve the effectiveness of nutrition and stool quality in rats which have undergone restorative proctocolectomy. Simultaneously, it increases the intensity of pouch adaptation and inflammation. The specificity of observed changes is not clear. However, it may imply potential modulation of inflammatory processes of pouch mucosa. (Folia Histochemica et Cytobiologica 2012; Vol 50, No. 1, pp. 125-129)
\end{abstract}

Key words: restorative proctocolectomy, J-pouch, pouchitis, docosahexaenoic acid

\section{Introduction}

Restorative proctocolectomy with ileal pouch-anal anastomosis is a procedure consisting of excision of the entire colon, creation of an ileal reservoir and

Correspondence address: J. Walkowiak,

$1^{\text {st }}$ Chair of Pediatrics, Department of Gastroenterology and Metabolism, Poznan University of Medical Sciences, Szpitalna Str. 27/33, 60-572, Poznan, Poland; tel.: + 486184803 10, fax: + 486184833 62; e-mail: jarwalk@ump.edu.pl anastomosing it with preserved anal sphincters. The major indications for proctocolectomy embrace ulcerative colitis (UC) and familial adenomatous polyposis (FAP) [1,2]. As with any surgery, it implies the possibility of postoperative complications, the commonest being pouchitis $[3,4]$. According to the available data, it occurs in 5-60\% of patients who undergo surgery [4-6]. The diagnosis of pouchitis is based on the Pouchitis Disease Activity Index (PDAI), which combines clinical, endoscopic and histological criteria (Moskowitz scale). For the evaluation of adaptive changes, the Laumonier scale is used [7]. 
Docosahexaenoic acid (DHA) belongs to the family of n-3 long-chain polyunsaturated fatty acids (LCPUFA), which de novo cannot be synthesized in humans $[8,9]$. It is assumed that n-3 LCPUFAs exhibit anti-inflammatory activity. Long-term consumption of DHA and eicosapentaenoic acid (EPA) may increase their tissue levels, simultaneously decreasing the concentration of arachidonic acid (AA). EPA and DHA replace AA in tissue lipids, serum and thrombocyte membranes. As a result, the synthesis of AA-derived eicosanoids decreases, potentially inhibiting inflammation $[8,9]$.

Several controlled studies using dietary (in the form of fish oil) patients with inflammatory bowel disease (IBD) have been conducted [10-14]. Although some trials have reported clinical improvement (e.g. improved gut histology, decreased disease activity, decreased use of corticosteroids, and decreased number of relapses), when these trials have been pooled, no consistently strong clinical effect has emerged [8]. However, the selection of potential placebo was diverse, i.e. sunflower oil, corn oil, olive oil, short-chain fatty acids and mixed oil. Moreover, the selection and number of patients and duration of interventions also differed. The results obtained in an animal model of colitis were more homogenous and convincing. There is no data on the effect of n-3 LCPUFA supplementation either in a human or an animal study.

Interestingly, it has been documented in the animal model of cystic fibrosis that DHA supplementation reduces inflammatory and destructive processes in different organs, also in the small intestine. Therefore in the present study we aimed to determine the influence of pure DHA supplementation on the expression of rat intestinal inflammation, the effectiveness of feeding, and the quality of stools in rats which had undergone a restorative proctocolectomy.

\section{Material and methods}

After a seven day period of adaptation, and 24-hour fasting, 24 animals underwent restorative proctocolectomy with the creation of a J-pouch [15]. The strictured ileo-anal anastomosis was performed intraoperatively. The stricture is one of the causes of pouchitis both in clinical and experimental models [16-18]. After one day of fasting (exclusive supply of $8 \%$ glucose solution), the animals received a semi-synthetic diet without fiber (AIN-93) in increasing doses for ten days (respectively 5, 8, 10 and $12 \mathrm{~g} / \mathrm{d}$ in the following days, up to $25 \mathrm{~g} / \mathrm{d}$ ) [19]. Subsequently, the inflammation of the J-pouch was induced in a model developed in our own previous studies. For the following 11 days, the rats received the same diet (up to $25 \mathrm{~g} / \mathrm{d}$ ). For that purpose over the next seven days, all animals were administered feed AIN-93 supplemented with fiber (in growing quantities, i.e. $1 \%$ on the first day, $2 \%$ on the second, up to a maximum of $4 \%$ con- tent). Subsequently, rats were allocated according to body weight and then randomly divided into three equal subgroups (the control group and two supplementation groups). Animals from the control group were fed ad libitum a semisynthetic diet AIN-93 for a period of six weeks. Rats from the supplementation groups received the same diet enriched with DHA (Laborest Italia SpA, Mediolan, Italy):

- at a dose of $500 \mathrm{mg} / \mathrm{rat} /$ day (additional vitamin E - as an antioxidant agent according to Harris ratio - 0.010 $\mathrm{g} / \mathrm{kg}$ of diet mass) in the high dose group (HD);

- at a dose of $250 \mathrm{mg} / \mathrm{rat} /$ day (additional vitamin $\mathrm{E}$ $0.005 \mathrm{~g} / \mathrm{kg}$ of diet mass) in the low dose group (LD).

Diets were prepared in a powdered form. The animals had continuous access to food.

The quality of stools, body weight gains and energy intakes (based upon feed intake) were assessed every day throughout the study. The effectiveness of feeding (ratio between daily energy intake and daily weight gain) was also calculated. All of the rats survived to the end of the study. The animals were then euthanized, and specimens of J-pouch mucosa for the histopathological and immunohistochemical analysis were obtained.

All surgical procedures were conducted by one qualified surgeon in accordance with the guidelines of the European Community Council directives 86/609/EEC and with the approval of the Local Ethics Committee (42/2006).

Quality of stool. For the assessment of stool quality, a 5-point scale was used (1 - lack of stool, 2 - diarrhea, 3 blob of stool, 4 - textured stool, 5 - normal stool). Since such an assessment was expected potentially to be subjective, the observer was 'blinded' to the animal group selection and the sample origin (MT).

Histopathological examination. Microscopic assessment was performed according to standard histological techniques (hematoxylin and eosin staining). In addition to routine histopathological examination, the collected specimens were evaluated for the intensity of inflammation (Moskowitz scale) and the adaptation changes with intestinal villous shortening (Laumonier scale) [7].

Immunohistochemical examination. Tissue expression of selected pro- (IL-1 $\alpha, 6,12)$ and anti-inflammatory (IL-10) interleukins was evaluated using the $\mathrm{ABC}$ technique (Avidin-Biotin Complex) using a LSAB PLUS kit Kit/HRP (DakoCytomation, Glostrup, Denmark) [20]. The color was developed for $90 \mathrm{~s}$ using a Vector DAB substrate kit and counterstained with Meyer's hematoxylin (Vector Laboratories, Burlingame, CA, USA). The presence or absence of cells with immunohistochemical reaction was assessed (assuming that honey-brown cytoplasm staining was equivalent to a positive reaction) in a scale from 0 to $3(+)$. The interleukins were evaluated in epithelial cells and mononuclear inflammatory cells (macrophages and lymphocytes). 
Colonic histopathological preparations of patients with active ulcerative colitis (UC) served as a positive control. Those preparations in which during the immunohistochemical staining the addition of a first antibody was omitted, created a negative control. Immunohistochemical scoring was determined by counting IL- $1 \alpha, 6,10,12$-immunoreactive cells on photomicrographs obtained from five random high-power microscopic fields $(400 \times$ magnification $)$.

Both histological and immunohistochemical assessment was performed by a blinded histopathologist (PM).

Statistical analysis. For the parametric values, means and standard deviations (SD) were calculated, while for the nonparametric values, ranges were given. For both, medians were provided. Statistical analysis of data was performed using the Kruskal-Wallis test with post-hoc comparisons.

\section{Results}

Body weight gains, energy intakes, the effectiveness of feeding and the quality of stools during the supplementation period of the study are presented in Table 1 . The effectiveness of feeding was significantly better in HD than in LD and CG. Moreover, the quality of stools was significantly better in HD than in CG.

The severity of inflammation, expressed in the Moskowitz scale, and the degree of pouch adaptation, expressed in the Laumonier scale, are present- ed in Table 2. The severity of inflammation was greater in HD and LD than in CG. However, pouch adaptation was more significant in LD than in CG.

Tissue expression of proinflammatory (IL- $1 \alpha$, IL- 6 and IL-12) and anti-inflammatory (IL-10) interleukins in pouch samples is summarized in Table 3 . The expression of IL-6 and IL-12 was comparable in all analyzed groups. Nevertheless, tissue expression of IL- $1 \alpha$ and IL-10 was higher in HD and LD than in CG.

\section{Discussion}

The influence of nutritional modifications on the feeding effectiveness and expression of pouchitis in rats which have undergone a procedure of restorative proctocolectomy was studied in the present study. The use of pure DHA has been extrapolated from a mouse model of cystic fibrosis $(\mathrm{CF})$ in which it was demonstrated that DHA supply leads to a decline of inflammatory and destructive processes in the involved organs (lungs, pancreas and intestine) [21]. The choice of an adequate supplementation dose was a difficult challenge. ACF mouse model was taken as a reference, in which the DHA was administered at a dose of $40 \mathrm{mg} / \mathrm{day} / \mathrm{mouse}$ [22].

Restorative proctocolectomy implies the need for entire large bowel resection. In humans, for around three months, loop ileostomy is usually created, but there is also a group of patients without ileostomy. In

Table 1. Body weight gains (BWG), energy intakes (EI), effectiveness of feeding (EF) and quality of stools (QS) during the supplementation period of the study

\begin{tabular}{|c|c|c|c|c|}
\hline \multirow{2}{*}{$\begin{array}{l}\text { Estimated } \\
\text { parameter }\end{array}$} & HD & LD & CG & \multirow[t]{2}{*}{$\mathbf{p}$} \\
\hline & Median (mean \pm SD) & Median $($ mean \pm SD) & Median $($ mean \pm SD) & \\
\hline BWG [g/day] & $\begin{array}{c}2.5 \\
(2.5 \pm 0.4)\end{array}$ & $\begin{array}{c}1.8 \\
(1.9 \pm 0.6)\end{array}$ & $\begin{array}{c}1.8 \\
(1.9 \pm 0.5)\end{array}$ & NS \\
\hline EI [kcal] & $\begin{array}{c}96.7 \\
(96.4 \pm 5.8)\end{array}$ & $\begin{array}{c}95.4 \\
(95.4 \pm 4.2)\end{array}$ & $\begin{array}{c}99.1 \\
(98.5 \pm 8.0)\end{array}$ & NS \\
\hline $\mathrm{EF}[\mathrm{kcal} / \mathrm{g}]$ & $\begin{array}{c}37.9 \\
(39.4 \pm 4.9)\end{array}$ & $\begin{array}{c}50.6 \\
(55.5 \pm 21.1)\end{array}$ & $\begin{array}{c}53.9 \\
(54.8 \pm 14.4)\end{array}$ & HD vs. $C G \mathrm{p}=0.01$ \\
\hline QS* & $4(3-5)$ & $4(3-5)$ & $4(2-5)$ & HD vs. $C G p=0.004$ \\
\hline
\end{tabular}

*Median and range are given; HD — High dose group; LD — Low dose group; CG — Control group; NS — not significant

Table 2. Severity of inflammation (MS, Moskowitz scale) and degree of pouch adaptation (LS, Laumonier scale) during the supplementation period of the study

\begin{tabular}{|l|c|c|c|c|}
\hline \multirow{2}{*}{$\begin{array}{l}\text { Estimated } \\
\text { parameter }\end{array}$} & HD & LD & CG & \multirow{2}{*}{ Statistical significance } \\
\cline { 2 - 4 } & Median (range) & Median (range) & Median (range) & \\
\hline MS & $5(2-6)$ & $5(4-6)$ & $2(2-3)$ & $\begin{array}{c}\text { HD vs. CG } p=0.03 \\
\text { LD vs. CG } p=0.0006\end{array}$ \\
\hline LS & $2(1-3)$ & $3(2-4)$ & $1(1-2)$ & LD vs. CG $p=0.007$ \\
\hline
\end{tabular}

HD - High dose group; LD — Low dose group; CG — Control group 
Table 3. Tissue expression of proinflammatory and anti-inflammatory interleukins in pouch samples

\begin{tabular}{|l|c|c|c|c|}
\hline \multirow{2}{*}{$\begin{array}{l}\text { Estimated } \\
\text { parameter }\end{array}$} & HD & LD & CG & \multirow{2}{*}{ Statistical significance } \\
\cline { 2 - 5 } & Median (range) & Median (range) & Median (range) & \\
\hline IL-1 $\alpha$ & $2(1-3)$ & $2(1-2)$ & $1(1-1)$ & $\begin{array}{c}\text { HD vs. CG } p=0.009 \\
\text { LD vs. CG } p=0.05\end{array}$ \\
\hline IL-6 & $1(1-3)$ & $2(1-3)$ & $1(1-1)$ & NS \\
\hline IL-12 & $2(1-3)$ & $2.5(1-3)$ & $1(1-2)$ & NS \\
\hline IL-10 & $3(2-3)$ & $3(2-3)$ & $2(1-2)$ & $\begin{array}{c}\text { HD vs. CG } p=0.04 \\
\text { LD vs. CG } p=0.04\end{array}$ \\
\hline
\end{tabular}

HD — High dose group; LD — Low dose group; CG — Control group; NS — not significant

selected cases, the functional results for both types of the procedure, i.e. with and without loop ileostomy, are similar. In rats, a one-step procedure was done and the ileostomy was omitted. Therefore, the pouch was exposed to feces immediately after the procedure. This resulted in severe diarrhea, which was observed in animals for one week after the surgery. In the course of the experiment, the consistency of stools improved until they were formed, and sometimes were even normal. Stool quality and the effectiveness of feeding were documented to be better in HD than CG. In the majority of studies, such parameters are not recorded. Studies carried out in UC patients suggest that n-3 LCPUFA supplementation may lead not only to the decline of inflammation, but also to the reduction of disease activity and the amelioration of symptoms $[10,11,23]$. In a crossover study, 11 UC patients received either a mixture of n-3 PUFA (at a daily dose of $2.7 \mathrm{~g}$ EPA and $1.8 \mathrm{~g}$ DHA) or a placebo i.e. corn oil (at a dose of $4.2 \mathrm{~g} /$ day). After eight months of the nutritional modification, a $56 \%$ reduction of disease activity in the Truelove-Witts scale was observed. In the mentioned scale, the quality of stool (the presence of fresh blood and the number of diarrheal stools) was considered [23].

The intensity of inflammation was more severe in DHA groups than in the control group which received a regular diet of AIN-93. In some rats from the HD and $\mathrm{LD}$ groups, it even reached the highest degree (six points). These obtained results raise important questions. Histopathological results suggested a worsening course of the disease. However, clinical improvement may imply a more complicated situation. The intensive pouchitis observed in the present study in rats from the DHA groups may be the result of massive modulation and reconstruction of the pouch, which could be considered as a beneficial process [24]. This thesis was suggested by Vanderhoof et al, who described the beneficial effect of a LCPUFA-enriched diet, especially linolenic acid (n-3 family), with the increased intensity of proliferation and modulation of the jejunal mucosa epithelium [25].

Intestinal inflammation is activated by several factors e.g. pro-inflammatory cytokines.
In the present study, we saw higher IL-1 $\alpha$ activity in pouch samples in DHA groups compared to the control group. IL-1 $\alpha$ correlated with the intensity of pouchitis using the Moskowitz scale. These results are not concordant with available data. Medium enrichment with EPA and DHA in cells cultures has resulted in inhibition of production of IL- $1 \beta$ by monocytes and IL- 6 by endothelial cells [26, 27]. It has been demonstrated in similar human studies that $n-3$ acids supplementation (EPA + + DHA at doses above $2 \mathrm{~g}$ /day) in healthy volunteers reduces IL-1 and IL- 6 production [28, 29]. It should be underlined that in compared studies, a mixture of n-3 fatty acids, and not pure DHA, was used. In addition, only healthy subjects or cell cultures were assessed and the dose of n-3 fatty acids was significantly lower.

IL-10 belongs to anti-inflammatory interleukins [30]. In the present study, the expression of IL-10 was statistically higher in DHA groups than in the control group. Our data is concordant with the findings of Bradley et al., who reported increased tissue activity of IL-10 and its higher gene expression in adipocyte cell cultures due to addition of DHA, unlike palmitic acid and oleic acid [31]. The results obtained by Sierra et al. suggest that the addition of EPA could have a more significant effect than DHA. In that study, Balb/c mice were fed with three different diets: standard (based on sunflower oil), fish oil plus EPA-enriched (approximately $6.2 \pm 0.9 \mathrm{mg} / \mathrm{day}$ ), and fish oil plus DHA-enriched (approximately $8.4 \pm 1.8 \mathrm{mg} /$ day) [32]. After three weeks of the supplementation, IL-10 concentrations in macrophages and lymphocytes in the group of animals supplemented with fish oil enriched in DHA were lower than in the group receiving a diet with fish oil enriched in EPA. However, a mixture of fatty acids (fish oil), and not pure DHA was used in this study.

In conclusion, DHA supplementation has no impact on body weight gain. Yet it seems that it may improve the effectiveness of nutrition and stool quality in rats which have undergone restorative proctocolectomy. Simultaneously, it increases the intensity of pouch adaptation and inflammation. The specificity of observed changes is not clear. However, it may imply potential modulation of inflammatory processes of pouch mucosa. 


\section{Acknowledgments}

This study was financed by University grants (Poznan University of Medical Sciences - 502-01-1103603-07588; Poznan University of Life Sciences - 261/TŻ/86/W).

The authors declare that they have no conflict of interest.

SDC, TB, JW: study concept and design, interpretation of data, statistical analysis, preparation of manuscript. MT: interpretation of data, care of animals, preparation of manuscript. ATR: interpretation of data. PM, MD: analysis of samples, interpretation of data.

\section{References}

1. Parks AG, Nicholls RJ. Proctocolectomy without ileostomy for ulcerative colitis. Br Med J. 1978;8:85-88.

2. Utsunomiya J, Iwama T, Imajo M et al. Total colectomy, mucosal proctectomy, and ileoanal anastomosis. Dis Colon Rectum. 1980;23:459-466.

3. Hoda KM, Collins JF, Knigge KL, Deveney KE. Predictors of pouchitis after ileal pouch-anal anastomosis: a retrospective review. Dis Colon Rectum. 2008;51:554-560.

4. Kuisma J, Nuutinen H, Luukkonen P, Järvinen H, Kahri A, Färkkilä M. Long term metabolic consequences of ileal pouch-anal anastomosis for ulcerative colitis. Am J Gastroenterol. 2001;96:3110-3116.

5. Kuisma J, Luukkonen P, Järvinen H, Kahri A, Färkkilä M. Risk of osteopenia after proctocolectomy and ileal pouchanal anastomosis for ulcerative colitis. Scand J Gastroenterol. 2002;37:171-176.

6. Ferrante M, Declerck S, De Hertogh G et al. Outcome after proctocolectomy with ileal pouch anal anastomosis for ulcerative colitis. Inflamm Bowel Dis. 2008;14:20-28.

7. Sandborn WJ, Tremaine WJ, Batts KP, Pemberton JH, Phillips SF. Pouchitis after ileal pouch-anal anastomosis: a Pouchitis Disease Activity Index. Mayo Clin Proc. 1994;69:409-415.

8. Calder PC. Polyunsaturated fatty acids, inflammatory processes and inflammatory bowel diseases. Mol Nutr Food Res. 2008;52:885-897.

9. Camuesco D, Comalada M, Concha A et al. Intestinal antiinflammatory activity of combined quercitrin and dietary olive oil supplemented with fish oil, rich in EPA and DHA (n-3) polyunsaturated fatty acids, in rats with DSS-induced colitis. Clin Nutr. 2006;25:466-476.

10. Aslan A, Triadafilopoulos G. Fish oil fatty acid supplementation in active ulcerative colitis: a double-blind, placebo-controlled, crossover study. Am J Gastroenterol. 1992;87:432-437.

11. Greenfield SM, Green AT, Teare JP et al. A randomized controlled study of evening primrose oil and fish oil in ulcerative colitis. Aliment Pharmacol Ther. 1993;7:159-166.

12. Belluzzi A, Brignola C, Campieri M, Pera A, Boschi S, Miglioli M. Effect of an enteric-coated fish-oil preparation on relapses in Crohn's disease. N Engl J Med. 1996;334:1557-1560.

13. Mantzaris GJ, Hatzis A, Archavlis E et al. The role of colonoscopy in the differential diagnosis of acute, severe hemorrhagic colitis. Endoscopy. 1995;27:645-653.

14. Varghese T, Coomansingh D. Clinical response of ulcerative colitis with dietary omega-3 fatty acids: a double-blind randomized study. Br J Surg. 2000;887:73.

15. Lichtman SN, Wang J, Hummel B, Lacey S, Sartor RB. A rat model of ileal pouch-rectal anastomosis. Inflamm Bowel Dis. 1998;4:187-195.
16. Gionchetti P, Morselli C, Rizzello F et al. Management of pouch dysfunction or pouchitis with an ileoanal pouch. Best Pract Res Clin Gastroenterol. 2004;18:993-1006.

17. Banasiewicz T, Marciniak R, Kaczmarek E et al. The diameter of the ileal J-pouch-anal anastomosis as an important risk factor of pouchitis - clinical observations. Med Sci Monit. 2011;7:91-96.

18. Stucchi AF, Shebani KO, Reed KL et al. Stasis predisposes ileal pouch inflammation in a rat model of ileal pouch-anal anastomosis. J Surg Res. 2009.

19. Reeves PG, Nielsen FH, Fahey GC Jr. AIN-93 purified diets for laboratory rodents: final report of the American Institute of Nutrition ad hoc writing committee on the reformulation of the AIN-76A rodent diet. J Nutr. 1993;123:1939-1951.

20. Nagle RB, Clark VA, McDaniel KM, Davis JR. Immunohistochemical demonstration of keratins in human ovarian neoplasms. A comparison of methods. J Histochem $C y$ tochem. 1983;3:1010-1014.

21. Pall H, Zaman MM, Andersson, Freedman SD. Decreased peroxisome proliferator activated receptor alpha is associated with bile duct injury in cystic fibrosis transmembrane conductance regulator-/- mice. J Pediatr Gastroenterol Nutr. 2003; 42:275-281.

22. Freedman SD, Weinstein D, Blanco PG et al. Characterization of LPS-induced lung inflammation in cftr-/- mice and the effect of docosahexaenoic acid. J Appl Physiol. 2002;92:2169-2176.

23. Almallah YZ, Ewen SW, El-Tahir A et al. Distal proctocolitis and $n-3$ polyunsaturated fatty acids (n-3 PUFAs): the mucosal effect in situ. J Clin Immunol. 2000;20:68-76.

24. Mantzioris E, Cleland LG, Gibson RA, Neumann MA, Demasi M, James MJ. Biochemical effect of a diet containing food enriched with n-3 fatty acids. Am J Clin Nutr. 2000;72:42-48.

25. Vanderhoof JA, Park JH, Herrington MK, Adrian TE. Effects of dietary menhaden oil on mucosal adaptation after small bowel resection in rats. Gastroenterology. 1994;106:94-99.

26. De Caterina R, Cybulsky MI, Clinton SK, Gimbrone MA $\mathrm{Jr}$, Libby P. The omega-3 fatty acid docosahexaenoate reduces cytokine-induced expression of proatherogenic and proinflammatory proteins in human endothelial cells. Arterioscler Thromb. 1994;14:1829-1836.

27. Khalfoun B, Thibault F, Watier H, Bardos P, Lebranchu Y. Docosahexaenoic and eicosapentaenoic acids inhibit in vitro human endothelial cell production of interleukin-6. $A d v \operatorname{Exp}$ Med Biol. 1997;400:589-597.

28. Caughey GE, Mantzioris E, Gibson RA, Cleland LG, James MJ. The effect on human tumor necrosis factor alpha and interleukin 1 beta production of diets enriched in n-3 fatty acids from vegetable oil or fish oil. Am J Clin Nutr. 1996;63:116-122.

29. Trebble T, Arden NK, Stroud MA et al. Inhibition of tumour necrosis factor-alpha and interleukin 6 production by mononuclear cells following dietary fish-oil supplementation in healthy men and response to antioxidant co-supplementation. Br J Nutr. 2003;90:405-412.

30. Groux H, O'Garra A, Bigler M et al. A CD4 ${ }^{+}$T-cell subset inhibits antigen-specific T-cell responses and prevents colitis. Nature. 1997;389:737-742.

31. Bradley RL, Fisher FF, Maratos-Flier E. Dietary fatty acids differentially regulate production of TNF alpha and IL-10 by murine 3T3-L1 adipocytes. Obesity. 2008;16:938-944.

32. Sierra S, Lara-Villoslada F, Comalada M, Olivares M, Xaus J. Dietary eicosapentaenoic acid and docosahexaenoic acid equally incorporate as decosahexaenoic acid but differ in inflammatory effects. Nutrition. 2008;24:245-225.

Submitted: 25 July, 2011

Accepted after reviews: 12 December, 2011 